\title{
Economic and Technical Analysis of the Construction and Maintenance of Professional Soccer Fields
}

\author{
Laura Cevenini ${ }^{1}$, Alessandro De Luca ${ }^{2}$, Rino Ghelfi ${ }^{1}$, Ilaria Pasini ${ }^{1}$ and Alberto Minelli ${ }^{1}$ \\ 1. Department of Agricultural Sciences, Faculty of Agriculture, Alma Mater Studiorum, University of Bologna, Viale Fanin, Bologna \\ 46,40127, Italy \\ 2. Italian Golf Federation, Viale Tiziano, Rome 74,00196, Italy
}

\begin{abstract}
The aim of this analysis is to compare and contrast the differences and similarities of the construction and maintenance of soccer fields, from both technical and economic points of view. Authors studied two samples: the first with totally modified top soil following the USGA (United States Golf Association) Specifications, all new top soil, as in USGA, called the Texas method; the second sample was natural soil mixed with ammendants and sand, in order to reduce compaction. This study compares the initial investments, performance during training and finally the cost of maintenance. The drainage system was the same for both samples.
\end{abstract}

Key words: Turf grass, management, USGA (United States Golf Association), top-soil, soccer fields.

\section{Introduction}

The FIGC (Italian Football Federation) establishes guidelines for soccer field construction. These guidelines pertain to the game, but do not take into consideration turf grass and underlayer construction. The underlayer, called top soil, is responsible for good or bad performance of turf grass under poor weather conditions.

There are many types of soccer fields, depending on its use. Public fields used by amateur teams are more used than stadiums, so the maintenance and problems arising are different. In the first case, the maintenance consists of mowing.

Professional football clubs usually have more than one soccer field for training. These fields are adapted to tolerate such training with careful maintenance.

The stadium is the less problematic field because it isused once a week, and normally has time to regrow.

Sport fields are more artificial than ornamental ones; the combination of soil, climate, and plants must be perfect and stable, particularly the proportion between

Corresponding author: Alberto Minelli, researcher, main research fields: arboriculture, urban green, and green design. plants, air and water merit consideration.

The different areas of a soccer field must support the plants and provide easy water downflow in any rainfall situation.

There are different types of sport fields due to different construction of layers and drainage system.

A traditional sport field is made on natural soil, with rarely thin sand layer. The porosity and permeability are guaranteed for the first period, but later decrease. Under the soil there is drainage, but it is limited in its functionality due to its depth.

A DIN (Deutsches Institutfur Normung-Deutsche Standardisation Institute) sport field is made by superficial sand layer on gravel layer (Fig. 1) and the drainage is under the two layers (DIN standard 1835/4).

A USGA (United States Golf Association) field (Texas Method) was adopted by USGA in 1960. The upper layer is thicker than other systems and guarantees better performance in term of footfall strength. It is made by mixture of silicasand and peat. The sand give strength and is not a compressed material. Under this layer there is thin-gravel and gravel. The diameter of sand is proportional to the 


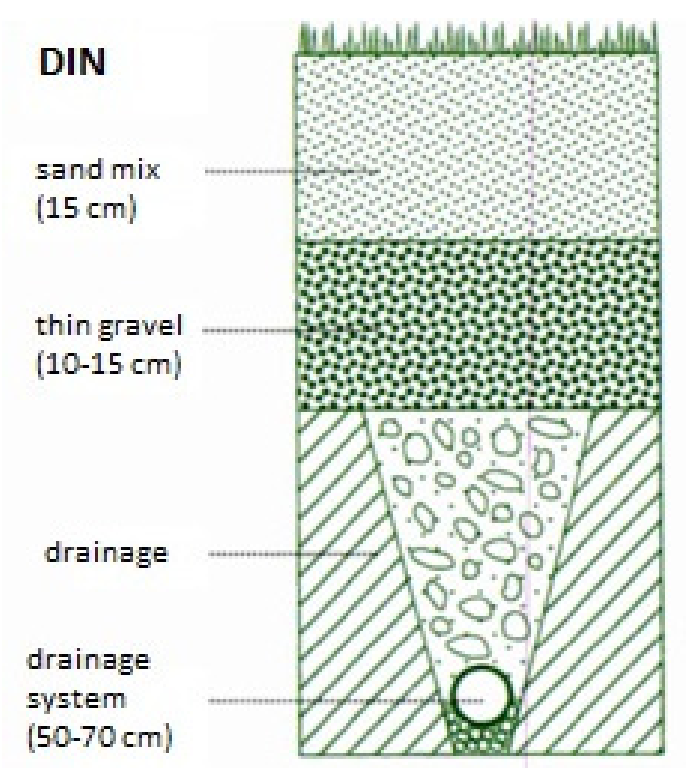

Fig. 1 Outline of DIN sport field (Beretta \&Vavassori, 2006).

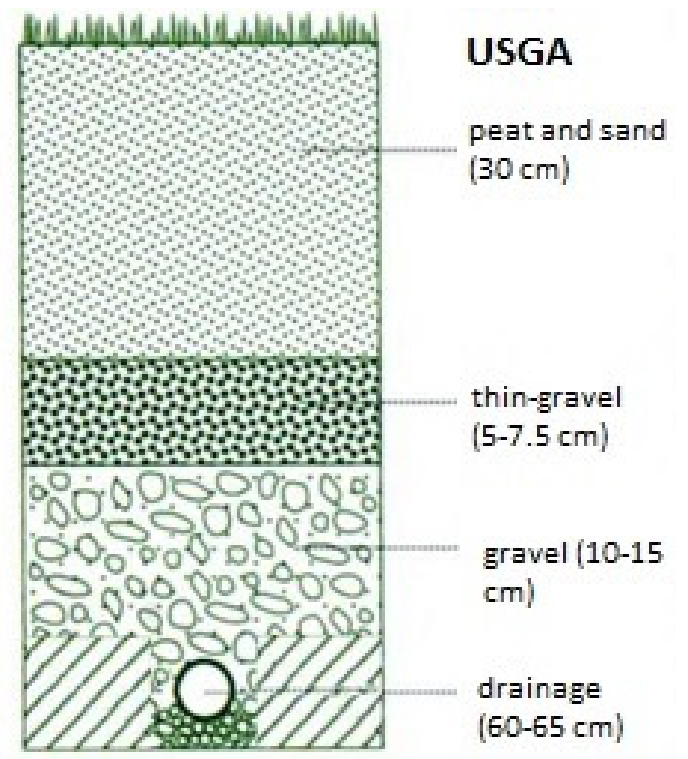

Fig. 2 Outlineos USGA sport field (Beretta \&Vavassori, 2006).

diameter of thin-gravel (Fig. 2). The drainage system is surrounded by thin-gravel [2].

Today, all high level sport fields are produced by sand mixed with drainage elements, irrigation and heating systems. Often the field is convexing to facilitate the water overflow. Drainage and convexing are palliative action to avoid compactation. A compact field is notable to work off water, and consequent water stagnation cause roots asphyxiation, disease increase and field decline. To maintain field efficiency is fundamental to avoid compact ation.

This problem can be solved by proper maintenance programs, including top dressing, fertilization, irrigation, correct mowing and sowing.

In this study, authors will examine two different types of sports fields: USGA and economic ones, which are different in top soil composition.

The initial investment, the performance and maintenance costs will be compared.

\section{Materials and Methods}

The fields studied are in Veronello, the Chievo Verona Headquarters near Verona, in the North-East part of Italy.

The fields are made up of Lolium perenne and Poa pratensis, with minimun amount of Poa annua, Trifoliumspp, Paspalumdisticum and Cyperusspp.

A $20 \mathrm{~cm}$ outline examination highlights a superficial layer $(5 \mathrm{~cm})$ with a considerable amount of sand and roots (photo 1 ).

The two fields were made according to technical documentation that contains generic information.

As already described, a sports field can be made following two different methods. USGA is the better method, not only for golf course, but also for fields with intense use. This method includes higher costs and is less widespread than the other method that consists of top soil less or further modified with amendant, organic substances and gravel.

The Veronello's field is part of this category: the natural soil was amended with sand in the first $10 \mathrm{~cm}$, the drainage is in the deep layer and the field is convexing.

The two types studied are very different, both in an economical sense and in technical characteristics.

In this study, authors want to evaluate the differences and economical sustainability.

The field subject of study is a regular soccer field $110 \times 70 \mathrm{~m}$ with irrigation, drainage system and professional turf grass. 


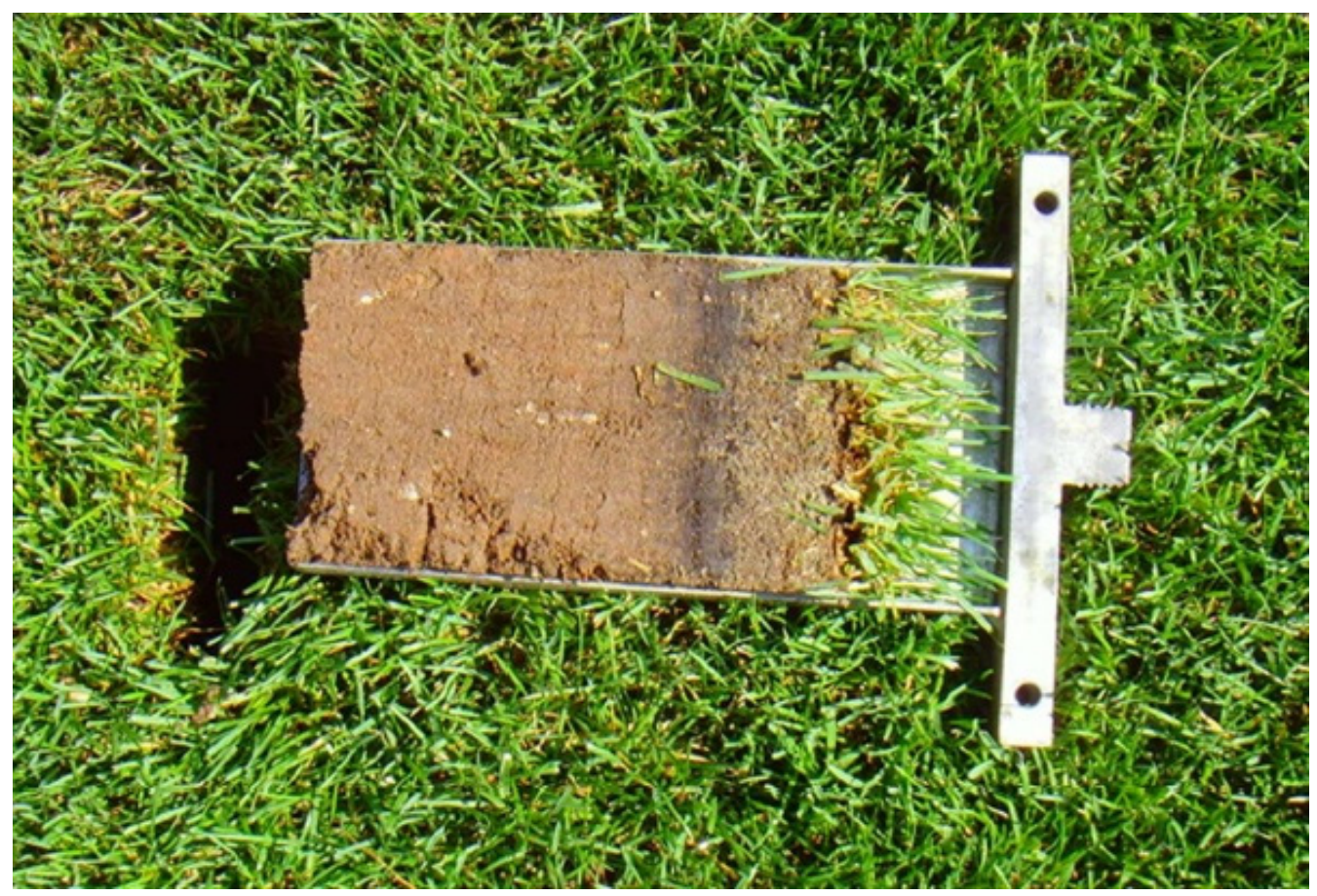

Photo 1 outline of training field.

The first type (A) follows the USGA standard: the drainage system consists of polyethylene tubes surrounded by $3-5 \mathrm{~cm}$ of thin-gravel. The gravel layer covers the drainage for a thickness of $10 \mathrm{~cm}$. The diameter of gravelis 6-10 $\mathrm{mm}$ and permits an efficient water overflow.

Above the gravel, there is a big-sand layer, the thickness is $5 \mathrm{~cm}$ and the diameter is $1-4 \mathrm{~mm}$. The big-sand prevents the infiltration of sand into gravel layer, and regulates the water flux.

The water passes from sand to big-sand, when this layer was satured, fall to gravel layer and drainage system. If the system is not satured, the water is available for turf grass.

As previously described, the big-sand is the sand-organic top soil. The amount of sand is generally around $80-90 \%$ and organic substances $10-20 \%$. In the case study, a new turf grass is expected to be made by direct seeding.

In the second type (B), the top soil is made by big-sand mixed with silicasand. The percentage is $50 \%$ for nig-sand (1-4 mm diameter) and 50\% of silicasand. In this case the use of lawn roll is expected.

\section{Results}

\subsection{Realization Costs}

Table 1 list the realization costs of two type of fields: drainage and irrigation systems, drainage linking, seeding and topsoil realization. Maintenance costs include agronomical operations to avoid perfect growth of young turf grass.

Type A is clearly the most expensive method. The differences between these two types are minimal but fundamental, because they define the performance of each system. Different top soils cause different performance in case of intense rainfall.

\subsection{Maintenance Costs}

For better performance of the two types of fields, different management is required. To make a comprehensive and incisive comparison, authors chose to analyze the management of two top soil in three periods (1-5 years, 6-10 years and 11-15 years).

In Tables 1-3, the different maintenance plans are analyzed. 
Table 1 Summary of realization costs for two fields (A for USGA method, B for economicone).

\begin{tabular}{lll}
\hline & Test A & Test B \\
\hline Irrigation system & $€ 33.194,08$ & $€ 33.194,08$ \\
Drainage & $€ 39.109,60$ & $€ 39.109,60$ \\
Drainage linking & $€ 21.556,60$ & $€ 21.556,60$ \\
Top soil & $€ 227.694,60$ & $€ 227.694,60$ \\
Top soil B & & $€ 121.078,60$ \\
Turfgrass seeded & $€ 10.432,20$ & $€ 85.680,00$ \\
Rolling grass & & $€ 45.000,00$ \\
Maintenance & $€ 45.000,00$ & $€ 300.618,88$ \\
TOT & $€ 376.987,08$ & \\
\hline
\end{tabular}

Table 2 Cost analysis for short (1-5 years), medium (6-10 years) and long (11-15 years) period for USGA method.

\begin{tabular}{llllllllll}
\hline Operation & $\begin{array}{l}\text { Unit cost } \\
(€)\end{array}$ & Amount & $\begin{array}{l}\text { Cost } \\
(€)\end{array}$ & $\begin{array}{l}\text { Frequency } \\
\text { short p. }\end{array}$ & $\begin{array}{l}\text { Frequency } \\
\text { medium p. long p. }\end{array}$ & $\begin{array}{l}\text { Frequency } \\
\text { period }(€)\end{array}$ & $\begin{array}{l}\text { Tot Medium } \\
\text { period }(€)\end{array}$ & $\begin{array}{l}\text { Tot Long } \\
\text { period }(€)\end{array}$ \\
\hline Mowing & 0.07 & $7,140 \mathrm{mq}$ & 499.80 & 110 & 110 & 110 & $54,978.00$ & $54,978.00$ & $54,987.00$ \\
Fertilization & 0.35 & $7,140 \mathrm{mq}$ & $2,499.00$ & 6 & 6 & 6 & $14,994.00$ & $14,994.00$ & $14,994.00$ \\
Verti-Drain & 0.21 & $7,140 \mathrm{mq}$ & $1,499.40$ & 4 & 4 & 4 & 5997.60 & $5,997.60$ & $5,997.60$ \\
Verticut & 0.15 & 7,140 & $1,071.00$ & 1 & 1 & 1 & $1,071.00$ & $1,071.00$ & $1,071.00$ \\
Logging & 0.30 & 7,140 & $2,142.00$ & 3 & 3 & 3 & $6,426.00$ & $6,426.00$ & $6,426.00$ \\
Top dressing & 0.60 & 7,140 & $4,284.00$ & 4 & 4 & 4 & $17,136.00$ & $17,136.00$ & $17,136.00$ \\
Tamping & 0.05 & 7,140 & 357.00 & 2 & 2 & 2 & 714.00 & 714.00 & 714.00 \\
Cleaning & 0.65 & 7,140 & $4,641.00$ & 6 & 6 & 6 & $27,846.00$ & $27,846.00$ & $27,846.00$ \\
Disease control & 0.14 & 7,140 & 999.60 & 4 & 4 & 4 & $3,998.40$ & $3,998.40$ & $3,998.40$ \\
Irrigation & 3.50 & $40 \mathrm{mc}$ & 140.00 & 90 & 90 & 90 & $12,600.00$ & $12,600.00$ & $12,600.00$ \\
Advice & 105.00 & $1 \mathrm{~h}$ & 105.00 & 20 & 20 & 20 & $2,100.00$ & $2,100.00$ & $2,100.00$ \\
TOT & & & & & & & $14,7861.00$ & $14,7861.00$ & $14,7861.00$ \\
\hline
\end{tabular}

Table 3 Cost analysis for short (1-5 years), medium (6-10 years) and long (11-15 years) period for economic top soil.

\begin{tabular}{llllllllll}
\hline Operation & $\begin{array}{l}\text { Unit cost } \\
(€)\end{array}$ & \multirow{2}{*}{ Amount } & $\begin{array}{l}\text { Cost } \\
(€)\end{array}$ & $\begin{array}{l}\text { Frequency } \\
\text { short } \mathrm{p} .\end{array}$ & $\begin{array}{l}\text { Frequency } \\
\text { medium p. }\end{array}$ & $\begin{array}{l}\text { Frequency } \mathrm{p} \text {. } \\
\text { lon }\end{array}$ & $\begin{array}{l}\text { Tot Short } \\
\text { period }(€)\end{array}$ & $\begin{array}{l}\text { Tot Medium } \\
\text { period }(€)\end{array}$ & $\begin{array}{l}\text { Tot Long } \\
\text { period }(€)\end{array}$ \\
\hline Mowing & 0.07 & $7,140 \mathrm{mq}$ & 499.80 & 110 & 110 & 110 & $54,978.00$ & $54,978.00$ & $54,987.00$ \\
Fertilization & 0.35 & $7,140 \mathrm{mq}$ & $2,499.00$ & 8 & 10 & 13 & $19,992.00$ & $24,990.00$ & $32,487.00$ \\
Verti-Drain & 0.21 & $7,140 \mathrm{mq}$ & $1,499.40$ & 7 & 10 & 12 & $10,495.80$ & $14,994.00$ & $17,992.80$ \\
Verticut & 0.15 & 7,140 & $1,071.00$ & 2 & 3 & 4 & $2,142.00$ & $3,213.00$ & $4,284.00$ \\
Logging & 0.30 & 7,140 & $2,142.00$ & 4 & 5 & 5 & $8,568.00$ & $10,710.00$ & $10,710.00$ \\
Top dressing & 0.60 & 7,140 & $4,284.00$ & 5 & 7 & 6 & $21,420.00$ & $29,988.00$ & $25,704.00$ \\
Tamping & 0.05 & 7,140 & 357.00 & 2 & 4 & 4 & 714.00 & $1,428.00$ & $1,428.00$ \\
Cleaning & 0.65 & 7,140 & $4,641.00$ & 6 & 6 & 6 & $27,846.00$ & $27,846.00$ & $27,846.00$ \\
Disease control & 0.14 & 7,140 & 999.60 & 4 & 8 & 10 & $3,998.40$ & $7,996.80$ & $9,996.00$ \\
Irrigation & 3.50 & $40 \mathrm{mc}$ & 140.00 & 90 & 90 & 90 & $12,600.00$ & $12,600.00$ & $12,600.00$ \\
Advice & 105.00 & $1 \mathrm{~h}$ & 105.00 & 28 & 32 & 60 & $2,940.00$ & $3,360.00$ & $6,300.00$ \\
TOT & & & & & & & $165,694.20$ & $192,103.80$ & $204,325.80$ \\
\hline
\end{tabular}

The tables clearly differentiate the type of management of the two fields. With the USGA method, the costs are the same period after period, but there are considerable changes with the second top soil. This cost increases due to the decline of turf grass over time.
Aeration and de-compact ation (verti-drain and logging) increase with fertilization, pest, and disease control. The aging of the field causes diseases, compact ation, and stagnant water. With the increase of agronomic problems, the need of professional assistance increases. 
The performance of the USGA field does not decrease so quickly. Physical and mechanical characteristics are preserved for a long period of time.

\section{Conclusion and Discussion}

In Italy, there are no regulations for professional soccer field construction. This lack has led to various construction techniques, not always resulting in good performance.

This no-regulation implicate negative aspect such money loss for constant manage. The managemen to peration are very onerous for football clubs and not always guarantee the best performance.

The USGA method requires a high initial cost but, allows for the possibility to save money in the managemen to peration. This type of field is equilibrated and healthy, because the combination between air, plants and water is in equilibrium [4].

Soccer fields are used heavily in fall, winter and spring, and must be able to manage rainfall without stagnation, avoiding mechanical, physical and agronomical damage.

If the high initial cost is spread out over a long period of time, the football can better sustain the costs.

In this study, authors tried to demonstrate better performance, in terms of management and economical costs, of the USGA field and the economical one.

Regulations regarding construction methods by the FIGC would be desirable.

\section{References}

[1] De Luca, A., Falcinelli, M., Modestini, F. S., and Veronesi, F. 2006. "Turfgrasses: Care, Management and Maintenance of Public and Private Green Areas." Edagricole Editor.

[2] Beretta, D., and Vavassori, A. 2006. "Design, Installation and Care of Turfgrass." Giunti Editor.

[3] Amicabile, S. 2013. "New Course in Economics and Evaluation.” Hoepli Editor.

[4] Pazzaglia, A. 2015. "Technical and Economic Analysis of the Implementation, Maintenance and Management of Turfgrass for Professional Sporting Use." Thesis in Tesi di Laurea in Ornamental Green and Landscape Conservation. School of Agriculture and Veterinary Medicine, Alma Mater Studiorum Università di Bologna. 